\title{
30
}

\section{The Computer as Decision Making Tool in the Junior High School}

\author{
Nitza Sternheim \\ Ben Gurion Junior High School, 13 Biterman St., Petach-Tikvah, Israel
}

\begin{abstract}
These pages will describe the major role the computer plays nowadays in the pedagogical process, as experienced by us, the staff of the Ben Gurion Junior High School. The computer enables the collection and processing of all relevant data in a 'real time' fashion, thus enabling the continuous screening of the activities of all parties involved: staff, students and management. All problems wheter with the staff, the learning materials, or the students, are instantly identified, and corrective measures taken promptly. In this manner, the quality of management is greatly enhanced and school climate is upgraded.
\end{abstract}

Keyword Codes: J.1; K.3.1; K.4.3

Keywords: Administrative Data Processing; Computer Uses in Education; Organisational Impacts

\section{INTRODUCTION}

The Ben Gurion Junior High School, Petach-Tikvah caters for students from four feeder schools. It contains a population of about 720 students in twenty form rooms. The pupils come from different vicinities of Petach-Tikvah and from heterogeneous population strata, including the underprivileged, which requires extensive integration. The socio-economic gaps are enormous.

The teaching staff has consciously and conscientiously undertaken the task of coping with the difficulties and to prepare suitable learning material for the different needs of individual students. All learning materials are mapped out so that the core, expansion and enrichment are clearly discernible. The materials are written and edited accordingly. Sections out of textbooks are rewritten to accommodate personal needs. Audio-visual equipment, television, V.C.R. cassettes, radio, pictures and computers are incorporated too. Unique class rooms have been established for each individual subject, which all include a center, that contains a complete collection of materials appertaining to the particular subject. This ensuries easy access to material and equipment in a scholastic atmosphere that is both motivating and interesting for the learner.

The management has set easily attainable, clear goals that focus on encouraging high scholastic achievements. The existence of only a few, unequivocal and comprehensible rules and regulations as far as order and discipline are concerned, helps to keep violence at its lowest possible level.

There is a central body of teachers in each subject who conduct the development programs on both the scholastic and methodological levels, as well as giving mutual assistance and support. 
The computer as a pedagogical aid is a tool that supplies all the teachers with a device for planning, follow-up, control and evaluation of their pupils' achievements, thus enabling them to make the necessary improvements where and whenever needed.

\section{FOLLOW UP OF STUDENTS' ACHIEVEMENTS}

The teachers feed information concerning test results, quiz results, homework, special assignments and any other important data into the computer, thus enabling the classroom teacher, head of department, educational advisor and administrator to see the achievements of the students at any given time in any given class.

This follow-up gives a precise picture of the student's work, both as an individual and in relation to other students in his class, and also to his own previous achievements. It enables a follow-up of the entire three years that the student attends the school: his difficulties, his progress, and his social and scholastic integration.

The computer also gives the classroom teacher a holistic picture of the position of his class. A subject teacher can compare the achievements of each class with other classes which he teaches, between his subject and other subjects that the student studies, and in comparison with the achievements of his colleagues, teaching parallel to him.

When setting grade level tests (i.e., simultaneous tests for all classes of the same grade examining identical material), the computer can supply invaluable material for finding the pitfalls whether in the teaching method, the study material, the students' ability, or the setup of the classes.

The educational advisor is able to detect the students who have difficulties (and the types of difficulties) and to ensure that they get the appropriate assistance in the subject matter, or if necessary, emotional and psychological assistance.

This inclusive picture can contribute to the decision to change the structure of the classes involved. If there are too many learning problems in one class, on the one hand, or too many brilliant students, on the other extra hours or less hours can be assigned, and the inclusion of a special project, or lessening pressure can be stipulated. The achievements of a class or the identification of its problems will be taken into account when deciding which teachers should be teaching which classes. At the same time, the teacher's personality, teaching style and teaching methods, his approach to weak students, will all be taken into account as well when the subject is up for discussion.

\section{FOLLOW-UP OF TEACHERS' ACTIVITIES}

The information gained from the computer enables management to follow up on each and every teacher's work. Through the information on the students, it is possible to compare teachers teaching the same subject, between colleagues teaching different subjects in the same class, to check a teacher's activities and functioning during a three years' period. All this allows immediate action in resolving pedagogical problems.

The teams meet once a week. Each team can get information from the computer and discuss the results of a test or the achievements (or lack of achievements) attained during the semester and then decide whether to continue with the program, to revise the material that sprouted difficulties or even change the structure of the groups. The lateral information available from the computer is vital in coming to constructive and immediate conclusions. 


\section{FOLLOW-UP OF TEACHING METHODS}

The computer can give invaluable assistance in this area too. This is achieved by comparing results of quizzes and tests through calculating their distribution charts. When the goals are clearly defined in advance, the computer can check if the teaching materials in heterogeneous classes have really decreased the amount of failures in the different subjects measured, or whether the inclusion of the computer in the math program has brought about a significant decrease in the number of underachievers in that subject.

\section{CLASSROOM ORGANIZATION}

In the junior high school we remain loyal to the original concept of the reform in education, integration and heterogeneous learning. The classes are made up identically - as far as the number of boys and girls, learning achievements, new immigrants, weak and strong students, and discipline problems are concerned. The computer aids with this too, by organizing the learning groups, stipulating who needs extra tutoring, fitting the learner's program to his needs, and assigning the most suitable teacher to a class. When a computer report is scrutinized at the end of a specified period changes can be made in the class.

The computer data can also be used to decide in transfering students to where they may benefit most.

\section{IMPROVING SCHOOL CLIMATE}

Grades have always been a source of dispute and controversy between students, teachers and parents. Lines of parents waiting to speak to a teacher, continuing late into the night, usually end in dissatisfaction and tension. In order to correct this, uniform criteria for grades have been set up. The "value" of an examination, a quiz, homework, lesson participation and a special assignment is always the same in a given subject, independent of who the teacher is. The criteria are clearly formulated, printed out and distributed to teachers, students and parents.

On parents-day, each parent is presented with a page of information carrying the results of examinations, quizzes, homework assignments, and personal remarks. This prevents the student from concealing information about certain results from the parents, and arguments with teachers completely disappear. The computer also compels teachers to take into account all pertinent factors to the student's activity at school.

The constant follow-up of the students' results, raises the teachers' awareness to the need to find solutions for weak students, to develop subject classrooms in which all the diverse learning material is amassed, to motivate all students of all levels - including the weaker ones, to make progress. The constant follow-up of the students' results, raises the teachers' awareness to the need to find solutions for weak students, to develop subject classrooms in which all the diverse learning material is amassed, to motivate all students of all levels including the weaker ones, to make progress.

\section{TIME SAVER FOR THE TEACHER}

The Ben Gurion Junior High School deals with may different projects that cover all classes and groups of students over and above the usual learning curriculum. 
Subjects like the Israel Studies, Technology and Industry in Our Times, Environmental Studies, Learning Styles in the Heterogeneous Classroom and The Incorporation of Multimedia and the Computer in the Teaching Process are the main projects undertaken by our school. Enrichment in Biology, Drama, Dance and Sports are getting priority. Ben Gurion is also a community school, very active in the neighborhood.

All this means, that the teachers are overloaded both time-wise and work-wise. As a result, management must do its utmost to spare as much as possible of the teachers' time. This goal is achieved by inviting the teachers as little as possible to school meetings and by reducing other administrative chores. The services of the computer in this area are also invaluable. At meetings, lists of grades, charts and other documents are distributed to the participants who can then evaluate the status of each student and take corrective measures, both quickly and effectively. The number of participants in these meetings has also been reduced to the minimum: only the class-teacher, the educational advisor, the department head and the management representative are present.

\section{ASSISTANCE IN HANDLING ABSENTEEISM AND LATE COMERS}

The computer is used in order to handle the data regarding absentees, late-comers and disturbers. The teachers, who are relieved in this manner from the tedious toils of handling the data, are free from now on, to deal with the real problems behind it. They can discuss with the students, the parents the school-advisor and if need arises, they can obtain in difficult cases also support from management .

The students are also aware that the information about their misconduct is piling up in the computer and will be expressed in their report-cards. There is no way to erase the evidence or to change previous conclusions and decisions.

\section{COMPUTER PRINTING OF REPORT CARDS}

This has made the class teacher's role easier, not only insofar as he does no longer have to write out the report cards by hand, which took hours, but also by no longer having to tap the necessary information about grades from the various subject teachers. Many times also corrections were to be made. Then, calculations had also to be remade and the incorrect results substituted. Today the responsibility falls entirely on the subject teachers who enter the marks to the computer and verify them. But this task is also greatly alleviated by the use of optical sensing equipment.

On the other hand, management's control over the ongoing activity is greatly simplified, by the use of various analytical methods, which can easily discern the current status of reporting. In addition, incorrect and incomplete information can be easily uncovered by the students, and to avoid inconvenient clashes with them, the teachers must do their utmost in order to make everything as correct and complete as can be. In this manner, one of the major sources of tension between teachers and students has been obliterated and a pleasant and correct atmosphere has prevailed. 


\section{CONCLUSION}

The computer has succeeded in a short span of time to become the major aid in the pedagogical process. This achievement is the outcome of its capability in both storing and processing vast quantities of data, as well as in making complex decisions while reacting in 'real time'.

Raising awareness to existing learning difficulties or achievements, discerning social maladjustment and learning difficulties of students, uncovering malfunctioning staff members, managing disclipinary routines and geting a holistic and clear picture of the status of all major issues, has never been attainable to such an extent, before the nt of the computer.

Moreover we must mention that all this is accomplished easily and promptly (in 'real-time'), which enables management to take corrective measures at the right time.

Lastly, the existence and accessibility of unambiguous and verifiable data has also contributed extensively to the reduction of conflict among all the parties involved: management, teachers, students, and parents. 